\title{
Factors Influencing Computing Students' Readiness to Online Learning for Understanding Software Engineering Foundations in Saudi Arabia
}

\author{
Abdulaziz Alhubaishy \\ College of Computing and Informatics \\ Saudi Electronic University \\ Medinah, Saudi Arabia
}

\begin{abstract}
The spread of Coronavirus disease (COVID-19) has enforced most universities/institutions over the world to transform their educational models (face-to-face and blended) bearing in mind the online educational environments as a temporary substitute. Consequently, all universities/institutions in Saudi Arabia have requested their students to continue the learning process using online environments. This transition has provided an opportunity to deeply investigate possible challenges as well as factors that influence the adoption of online learning as a future educational model for undergraduate students. This research measures the current undergraduate students' readiness for online learning and investigates factors that influence their level of readiness. Firstly, the research proposes the adoption of a validated multidimensional instrument to measure undergraduate students' readiness for online learning in different universities. Secondly, the research elaborates the findings by an in-depth study that highlights the main obstacles that hinder computing students' readiness to learn Software Engineering (SE) foundations using online learning. The research adopts survey research to measure students' readiness and analyzes the data to extract the readiness levels of different dimensions of the adopted instrument. Furthermore, interviews were conducted to specify the influential factors on computing students' readiness levels regarding learning SE foundations. Results show that students' readiness level for online learning is within the acceptable range while some improvements are needed. Furthermore, the study found that students' cognition, willingness, ignorance, and the amount of assistant and help they receive play a significant role in the success/failure of the adoption of learning $\mathrm{SE}$ foundations through online environment.
\end{abstract}

Keywords-Readiness to online learning; software-engineering education; improving online learning; university students

\section{INTRODUCTION}

Online learning has brought many advantages to the discipline of education during this era. The continuous improvement of computers and the Internet has a positive impact on the growing adoption of online learning strategies by different educational institutions. The adoption of online learning is primarily related to different disciplines and dimensions, such as student's attitude and perception of tools [1]. Teaching and learning are also affected by cultural differences [2]. Different studies have drawn different results based on the investigated culture/region. Different scales have been developed to measure the influence of these dimensions on different cultures. Measuring the influence promotes new insights and exposes challenges that hinder the success of adopting online learning.
Software Engineering (SE) education is the area that requires using effective methods to ensure that theoretical foundations are linked to practical experience to narrow the gap between academia and industry [3]. The adoption of online education has motivated researchers to investigate how it can contribute to narrow this gap. Online SE education requires assuring the readiness of both educators and learners.

This research, in line with other researches in this area, seeks to investigate how undergraduate students are prepared to accept the online learning model for the future. It has adopted five dimensions measurement model, namely students' motivation, self-directed learning, control, computer/internet self-efficacy, and online communication self-efficacy, in order to explore the weak areas that might delay the success of adopting online learning models. To the best of our knowledge, all proposed studies are either outdated or have targeted participants from fewer number of institutions. Exploring these dimensions within the Saudi culture in different institutions provides us the current level of readiness along with insightful ideas on how to improve students' readiness for online learning and overcome possible challenges that might hinder learning some practical concepts such as SE foundations. Therefore, the various objectives of this research can be summarized in the following points:

1) Understanding the current abilities and attitudes of students.

2) Identifying students' motivation towards online learning.

3) Highlighting the influence of the non-linear sequence of studying materials using online environments as compared to a traditional linear sequence.

4) Understanding the current state of students' perception and ability to use technology.

5) Acquiring students' communication self-efficacy using online learning environments.

6) Investigating the challenges and factors that impact undergraduate students' readiness for learning SE foundations through online methods and how to overcome these challenges.

\section{LITERATURE REVIEW}

\section{A. Online Learning Readiness}

Readiness for online learning is a concept that is mainly defined as the learner's confidence in online communication, 
preferences of the online model over the traditional model, and the ability to be involved in online learning [4]. Researchers have validated different scales to measure student's readiness. One of the most adopted scales by the literature is the five dimensions scale developed by [5]. These measured dimensions include students' self-directed learning, motivation for learning, control, computer and internet self-efficacy, and online communication self-efficacy.

Each dimension in the scale has been extensively elaborated and defined by many authors, while a separate scale for each of these dimensions has been proposed and validated. For example, self-directed learning is the concept that encompasses students' initiative to discover their needs and learning goals besides identifying resources for learning and choosing the best method to implement strategies of learning and eventually evaluate their outcomes [4-6].

Sethi et al. have used a pre-validated scale for measuring the readiness of 789 students from three different universities in Pakistan [6]. The authors have concluded that there is a need for training female students about handling computers and the Internet. Furthermore, improving learner's motivation and online interaction are two issues that course designers must take into consideration.

In 2011, Chanchary and Islam have studied the readiness of three groups at Saudi university [7]. The study has found that despite the ability of students to use applications and tools, they were not comfortable in online communications. Interestingly, $73 \%$ students of the studied groups have expressed their unwillingness to adopt online learning as a substitute for traditional learning.

Recently, readiness of a total of 204 female students was measured at Princess Nourah Bint Abdulrahman University (PNU) in Saudi Arabia[8]. The study has found that participants had a high level of readiness towards online learning as a substitute for the traditional closed-circuit distance technology.

\section{B. Online-Learn Software Engineering}

The main issue in teaching SE fundamental courses is teaching theoretical foundations and relating them to a hand-on experience to narrow the gap between academia and industry [3]. Most universities tend to dedicate most of the time and effort during the semester for teaching theoretical part of the course. Researchers and practitioners work on narrowing the gap by creating a balance between theoretical and practical experience. However, this is a hard task because of many challenges and difficulties that are encountered by teachers and students per se.

Heredia et al. have surveyed the literature to elicit the current pedagogical teaching approaches used in teaching software process [9]. The authors have found that most of methods are lectures with few number of exercises or projects or both. The other approaches include gamification as a type of gamerelated methods, realism, simulation, and missing subjects. In addition to these approaches, Marques et al. have highlighted six categories of pedagogical approaches for teaching practical SE; case studies, open source, learn by doing, problem-based learning, service learning, and inverted classroom [10].
Despite the benefits of these pedagogical approaches, some challenges and obstacles still exist. For example, game-related methods approach has the ability to enhance students' motivation and their learning outcome [11]. However, it has created new challenges, such as the cost of the approach and the lack of empirical data, to examine its benefits along with the lack of unified steps for educators in SE [12]. Based on a recent systematic review, Garousi et al. have categorized the obstacles during adopting different methods of teaching software testing into challenges related to instructors and students as well as the challenges related to instructors [13]. Within the first category, the authors have identified three challenges, which are low motivation, learning new tools, and the need to increase cognitive load of students. Within the later category, course design has been identified as the main challenge in addition to time constraints, resources constraints, assessing students' progress, and the challenge of integrating testing with other courses.

Online teaching of SE adds the aforementioned challenges into the main challenges being faced while adopting pedagogical online teaching approach. Though online teaching pave the way for SE educators to enhance the utilization of new teaching methods over traditional ones that are time consuming and do not allow instructors to fully teach concepts during the class time, such as the tools for software testing education [13]. For example, it has been found that most of the courses that are taught using non-traditional pedagogical approaches, such as online and blended courses, and adopted the gamerelated approach in SE education have utilized the approach completely during the online part [12]. Among different areas in SE, software design, software process, requirement engineering, and testing were highlighted in the literature as the most taught areas using online approach [14].

By considering which methods can be utilized during online teaching of SE, there is a need to highlight the obstacles being faced while online teaching and synthesize them with obstacles of teaching SE in order to have a full understanding of the challenges that SE online education faces. For example, the level of computer and internet self-efficacy as a dimension for measuring students' readiness to online learning can influence the successful adoption of SE tools during online courses. This can be true when a SE course is taught during early semesters of an undergraduate program where level of computer and internet self-efficacy of some students is low which eventually hinders the success of utilizing SE methods through online courses. Another example is the learners' experience and readiness to learn by considering the age of learners; adult or teenager, and how these factors can influence the learning process [15]. Mora et al. have proposed and tested a gamification framework on Requirement Engineering (RE) course taught completely online for adult students (age $>25$ ) [16]. The researchers concluded that the proposed framework was able to improve the level of students' engagements and motivation during the online course.

\section{RESEARCH METHOD}

To achieve the research objectives, we adopted a mixedmethod research called explanatory sequential design strategy, which means that we adopted quantitative research followed by qualitative research as stated by [17]. Adopting the explanatory 
sequential design strategy allows us to highlight the weak areas that hinder undergraduate students' readiness to online learning besides understanding why and how these weak areas actually hinder the success of adopting the online learning for learning SE. Within a single study, Creswell have explained that adopting explanatory mixed method necessitates building the qualitative study based on the results of data analyzed via the quantitative phase [18]. The advantage of adopting this method lies in the fact that the research problem needs "more in-depth understanding of the quantitative results (often cultural relevance)" [18].

The first phase is accomplished by adopting the quantitative research in the form of survey strategy which concerns with validating a measurement model for students' readiness by controlling the activities of designing and disseminating questionnaires. The collected data measures the five dimensions of learners' readiness for online learning as proposed by [1]. In addition, demographic information from participants is collected to analyze the potential influence on their responses.

Unlike the number of studies conducted by different authors, such as [7] and [8], in which they have examined online readiness within a fewer number of regions, we examined online readiness of students by considering the five main regions in Saudi Arabia; Central region, Western region, Eastern Region, Southern region, and Northern region. The sample for this quantitative survey allows us to enhance our understanding of the current level of online readiness over a broader region.

We then adopted the qualitative study in the form of semistructured interviews to understand how the extracted weak dimensions have influence on students' readiness for online learning, especially for learning SE concepts. The interview allows us to gather information in different formats than when a quantitative strategy was used. Targeted information encompasses the challenges and reasons behind the weak dimensions and how they hinder the application of learning SE courses. Therefore, semi-structured interviews are adopted where a set of open-ended questions is designed based on the quantitative results as the explanatory sequential design suggests.

The interview questions have been created and divided into two main sections. The first section concerns with collecting information regarding the previous (i.e. before COVID-19 Outbreak) uses of any educational environment, online tool, or software to help students understand SE concepts. The section also extracts information about current (during COVID-19 Outbreak) uses of these online environments and tools. The main reason of this section is to understand whether there were early adoptions of online tools to teach SE concepts, or there was a substantial differentiation between the uses of these tools before and after the pandemic. The second section concerns with collecting more information on how weak levels of online readiness dimensions influence the utilization of teaching SE concepts and how improving all dimensions level leads to a better utilization. Analyzing the interview takes place through thematic analysis to extract the main themes that influence the level of online readiness. The thematic analysis process was followed as illustrated by [19], and the main themes were extracted as explained in Section IV-B.

\section{RESULTS}

\section{A. Results of Quantitative Study}

Over a period of three months, a total of 244 valid responses were collected and analyzed. Collected data shows diversity in some demographic variables. Regarding the gender, around $82 \%(\mathrm{~N}=200)$ of the responses were male and $18 \%(\mathrm{~N}=44)$ were female. In Saudi universities, female and male students are studying at different campuses. Even though the survey was conducted through online means, reaching to a larger pool of female students was obstacle because of the separation strategy in studying and teaching. Undergraduate participants constituted the majority of responses $97.13 \%(\mathrm{~N}=$ $237)$, and only $2.87 \%(\mathrm{~N}=7)$ were graduate students. This is because of the small number of graduate students as compared to undergraduate students. Regarding the year of study, around $60 \%$ of participants were in their first two years of study. Finally, even though the equal effort was paid to gather responses from all regions, respondents from Eastern, Western, and Central universities constituted more than $80 \%$ of total respondents. The least number of respondents were received from Northern universities followed by Southern universities. However, number of students in the later regions were much less than other three regions. Table I shows the demographic information of the survey respondents.

Reliability testing of the survey constructs was carried out by examining Cronbach's Alpha. A reliable construct shows Cronbach's Alpha value of 0.70 or above as stated by [20]. All five constructs showed acceptable values ranging from 0.70 to 0.79 as depicted in Table II. Learner Control reached the lowest acceptable value $(0.70)$ followed by computer/Internet selfefficacy (0.74). Relating this level of reliability to the original scale, we found that these two constructs suffered from the convergent validity where the values of AVE did not reach the threshold value of 0.50 as suggested by [21].

Table III shows the mean of each item along with the overall mean for each construct. All individual items scored above acceptable means (above 3.5), except one item "SDL3: I manage time well" which scored the lowest mean of 3.35. Overall means of constructs were found to be 3.51, 3.72, 3.72, 3.94, and 4.09 for Learner control, Self-directed learning, Online communication self-efficacy, Computer/Internet selfefficacy, and Motivation for learning respectively. Based on the five-point Likert scale we used in the survey, we divided the responses into four intervals. We then compared the mean of each construct with a proposed model that was introduced by [22]. However, the proposed model by [22] examines readiness by measuring different dimensions, which are Technology, Innovation, People, and Self-Development. Means falling within the first interval $(\bar{X}: 1.0-2.6)$ indicate that the students are not ready for the e-learning yet and need a lot of work regarding the respected dimension reflecting that mean. Means falling within the second interval $(\bar{X}: 2.6$ - 3.4) show that the dimension needs some work before becoming ready for online learning. Means that fall within the third interval $(\bar{X}: 3.4-4.2)$ and fourth interval $(\bar{X}: 4.2$ - 5.0) indicate the readiness, but with the need for some improvements to dimensions falling within the third interval. Therefore, the threshold of $\bar{X}$ should be more than or equal to 3.4. Fig. 1 shows the means of our survey constructs illustrating that all constructs achieved the threshold of accepted level of online readiness. The mean of 
TABLE I. DEMOgRaphic VARIABLES

\begin{tabular}{|l|l|l|l|}
\hline Variable & Category & Frequency & Percentage (\%) \\
\hline Gender & Male & 200 & 82 \\
& Female & 44 & 18 \\
\hline Education Level & Undergraduate & 237 & 97.13 \\
& Graduate & 7 & 2.87 \\
\hline Year of Study & Preparatory/First Year & 37 & 15.1 \\
& Second & 117 & 48.0 \\
& Third & 30 & 12.3 \\
& Forth & 21 & 8.6 \\
& Fifth & 39 & 16.0 \\
University Location & Western & 84 & 34.4 \\
Region) & Eastern & 89 & 36.5 \\
& Central & 39 & 16 \\
& Southern & 17 & 7 \\
\end{tabular}

TABle II. Cronbach's Alpha Reliability for the Survey Constructs

\begin{tabular}{|l|l|l|}
\hline Construct & Number of Items & Cronbach's Alpha \\
\hline Computer/Internet self-efficacy & 3 & 0.74 \\
Self-directed learning & 5 & 0.79 \\
Learner control & 3 & 0.70 \\
Motivation for learning & 4 & 0.75 \\
Online communication self-efficacy & 3 & 0.79 \\
\hline
\end{tabular}

each contracts ranges from $\bar{X}=3.51$ to $\bar{X}=4.09$, which denotes that all our constructs fall within the third interval where some improvements are needed.

\section{B. Results of Qualitative Study}

All survey participants were recruited to participate in the interviews. Of the pool of the participants, nine participants showed their interest to participate in the qualitative study, so the interviews were arranged and conducted. After a comprehensive analysis of the participants' interviews using the thematic analysis, four main themes were extracted and considered as the main barriers to the successful adoption of online SE learning methods. These themes are:

1) Students' cognition towards new learning methods. The overall perspective of many students is that the online learning cannot fully help students understand different SE concepts; rather, traditional learning is the most suitable method. Some of the codes that were extracted from participants regarding their cognition towards new learning methods include resistance to change, fear of technology, and lack of motivation for searching and practicing new online learning tools. Firstly, fear of transition from traditional learning methods, i.e. face-to-face learning, to a technology-based method appears as one of the most influential factors. Students are also suffering from the lack of encouragement and motivation to learn and search for new tools that help them understand different SE concepts. These factors have been identified as assistant contributors to adherence tendency towards traditional methods.

2) Student's ignorance of the tools and their benefits. A main highlighted theme is that students are actually not aware of the availability of different online teaching methods and tools and their benefits, and are unable to practice them because of lack of knowledge. It has been identified that almost most of online tools and methods, such as game-related methods, are not recognized by students. Still, theoretical explanations using traditional methods represent the main teaching style in many universities. Furthermore, students are actually not aware of different benefits that the online tools and methods can provide them. Within this theme, the awareness about the availability and benefits of these methods and tools has been recognized by a minor number of students, however it has been highlighted that their knowledge along with other contributing factors, such as lack of guidance, can prevent them from adopting these methods and tools at their own.

3) Students' willingness to follow traditional learning methods.

An interesting theme constructed from different codes concerns about the willingness of students to learn traditionally. The reasons behind this are based on their current experience of online learning where only face-to-face lectures are transferred to virtual classes during COVID-19 pandemic, and they have the lack of willingness to online learning, inability to link the learning outcome with online tools, lack of online communication and social interaction, and believes in lack of knowledge retention. Each of these reasons might hinder the successful adoption of any learning strategy that is based on online tools and methods.

4) Instructors' and departments' tendency towards new teaching methods and tools.

An important theme is related to instructors' behaviour towards teaching their students. Different students have emphasized that their instructors are following the traditional methods, and they have no tendency to provide them any resources or information rather than verbally explaining the concepts. Therefore, regarding the instructors' attitude, it has been found that most of them tend to traditional methods. Furthermore, there is the lack of provided resources by the department/college and inability to accomplish online learning activities because of lack of support and assistance.

\section{Discussion}

An intrinsic relationship was highlighted between these themes and the level of online readiness. Firstly, even though 
TABLE III. MEAN SCORES FOR THE ONLINE READINESS TO LEARN SCALE

\begin{tabular}{|c|c|c|c|}
\hline Construct & Item & $X$ & SD \\
\hline $\begin{array}{l}\text { Computer/Internet self- } \\
\text { efficacy }\end{array}$ & $\begin{array}{l}\text { CIS1: I feel confident in performing the basic functions of Microsoft Office programs (MS Word, } \\
\text { MS Excel, and MS PowerPoint). } \\
\text { CIS2: I feel confident in my knowledge and skills of how to manage software for online learning. } \\
\text { CIS3: I feel confident in using the Internet (Google, Yahoo) to find or gather information for online } \\
\text { learning. } \\
\text { Overall for CIS: }\end{array}$ & $\begin{array}{l}3.77 \\
3.89 \\
4.16 \\
3.94\end{array}$ & $\begin{array}{l}1.13 \\
1.11 \\
1.09 \\
1.11\end{array}$ \\
\hline Self-directed learning & $\begin{array}{l}\text { SDL1: I carry out my own study plan. } \\
\text { SDL2: I seek assistance when facing learning problems. } \\
\text { SDL3: I manage time well. } \\
\text { SDL4: I set up my learning goals } \\
\text { SDL5: I have higher expectations for my learning performance. } \\
\text { Overall for SDL: }\end{array}$ & $\begin{array}{l}3.96 \\
3.85 \\
3.35 \\
3.52 \\
3.93 \\
3.72\end{array}$ & $\begin{array}{l}1.12 \\
1.18 \\
1.21 \\
1.19 \\
1.11 \\
1.16\end{array}$ \\
\hline Learner control & $\begin{array}{l}\text { LC1: I can direct my own learning progress. } \\
\text { LC2: I am not distracted by other online activities when learning online (instant messages, Internet } \\
\text { surfing). } \\
\text { LC3: I repeated the online instructional materials on the basis of my needs. } \\
\text { Overall for LC: }\end{array}$ & $\begin{array}{l}3.79 \\
3.21 \\
3.54 \\
3.51\end{array}$ & $\begin{array}{l}1.08 \\
1.35 \\
1.16 \\
1.20\end{array}$ \\
\hline Motivation for learning & $\begin{array}{l}\text { MFL1: I am open to new ideas. } \\
\text { MFL2: I have motivation to learn. } \\
\text { MFL3: I improve from my mistakes. } \\
\text { MFL4: I like to share my ideas with others. } \\
\text { Overall for MFL: }\end{array}$ & $\begin{array}{l}4.13 \\
4.30 \\
4.20 \\
3.73 \\
4.09\end{array}$ & $\begin{array}{l}1.03 \\
1.02 \\
1.00 \\
1.25 \\
\\
1.08 \\
\end{array}$ \\
\hline $\begin{array}{l}\text { Online communication self- } \\
\text { efficacy }\end{array}$ & $\begin{array}{l}\text { OCS1: I feel confident in using online tools (email, discussion) to effectively communicate with } \\
\text { others. } \\
\text { OCS2: I feel confident in expressing myself (emotions and humor) through text. } \\
\text { OCS3: I feel confident in posting questions in online discussions. } \\
\text { Overall for OCS: } \\
\text { Overall }\end{array}$ & $\begin{array}{l}3.90 \\
3.57 \\
3.69 \\
3.72 \\
3.82 \\
\end{array}$ & $\begin{array}{l}1.21 \\
1.30 \\
1.26 \\
1.26 \\
1.56\end{array}$ \\
\hline
\end{tabular}

students' level of confidence in their knowledge and skills of how to manage a software for online learning is acceptable $(\bar{X}: 3.89)$ with the need for improvement, it has been found that students lack this level of confidence when it comes to a specific online tool, such as SE online software and tools. The reasons are mainly related to their cognition and/or ignorance of the new tools and methods. Therefore, learning SE concepts through online tools and methods is mainly affected by their confidence in skills and knowledge along with their confidence in knowledge and skills related to the designated tools for learning SE concepts.

Self-directed learning of undergraduate students was also found to be acceptable ( $\bar{X}: 3.72)$, but it needs some improvements. This has been found in the qualitative study related to the level of students' willingness to proceed with learning SE concepts using new tools and online learning methods. For example, managing the time is a main issue that was found where many students are not able to manage their time during learning and experiencing new online tools. The improvement can be ensured by providing students required training and workshops to enable them to effectively manage their time during online learning. Furthermore, students' willingness to seek for assistant when facing problems is lower than expectation. Therefore, it can be another area of improvement that can be handled.

Learner control is the weaker dimension that has been highlighted $(\bar{X}: 3.51)$ which needs more improvements to enhance the readiness of undergraduate students. Learner control has been mainly identified with two themes; students' cognition and willingness. Within the first, students are mainly dependent on their experience of traditional learning progress and are not familiar with the management technique to direct their learning progress when it comes to online learning of SE tools. Furthermore, students are mainly dependent on repeated instructions provided by instructors rather online instructional and guidance procedures on how to understand and practice the online tools. Within the later, students' willingness to online learning is claimed to be low because of the distraction and inability to focus during online learning. Distraction by other activities is considered the second most influential factor $(\bar{X}: 3.21)$ that needs to be considered and improved by adopting corrective action to attract students towards avoiding distraction during online learning. The correction actions can be focusing more on online course design, choosing the right tools, and motivating students.

Motivation for learning was the highest dimension $(\bar{X}$ : 4.09). Interestingly, when it comes to online learning, the qualitative study exhibits a low motivation among undergraduate students. Different students have explained that they are not as motivated to online study and using new tools as traditional learning. For example, a student has explained that his university has transferred the lab session virtually and used the repl.it software which is a platform for creating and sharing code online [23]. The student has mentioned "Even though we were encouraged to share our codes with the instructor, a few numbers of us have done that". The student continued explaining the situation by saying "We still do not feel that the instructor's online correction of our code motivates us the same amount as it has been done during the face-to-face corrections".

Finally, online communication self-efficacy was acceptable $(\bar{X}: 3.82)$ with the need for some improvements. The qualitative study has highlighted that the level of confidence by using online tools for communication is high, but the issue arises 


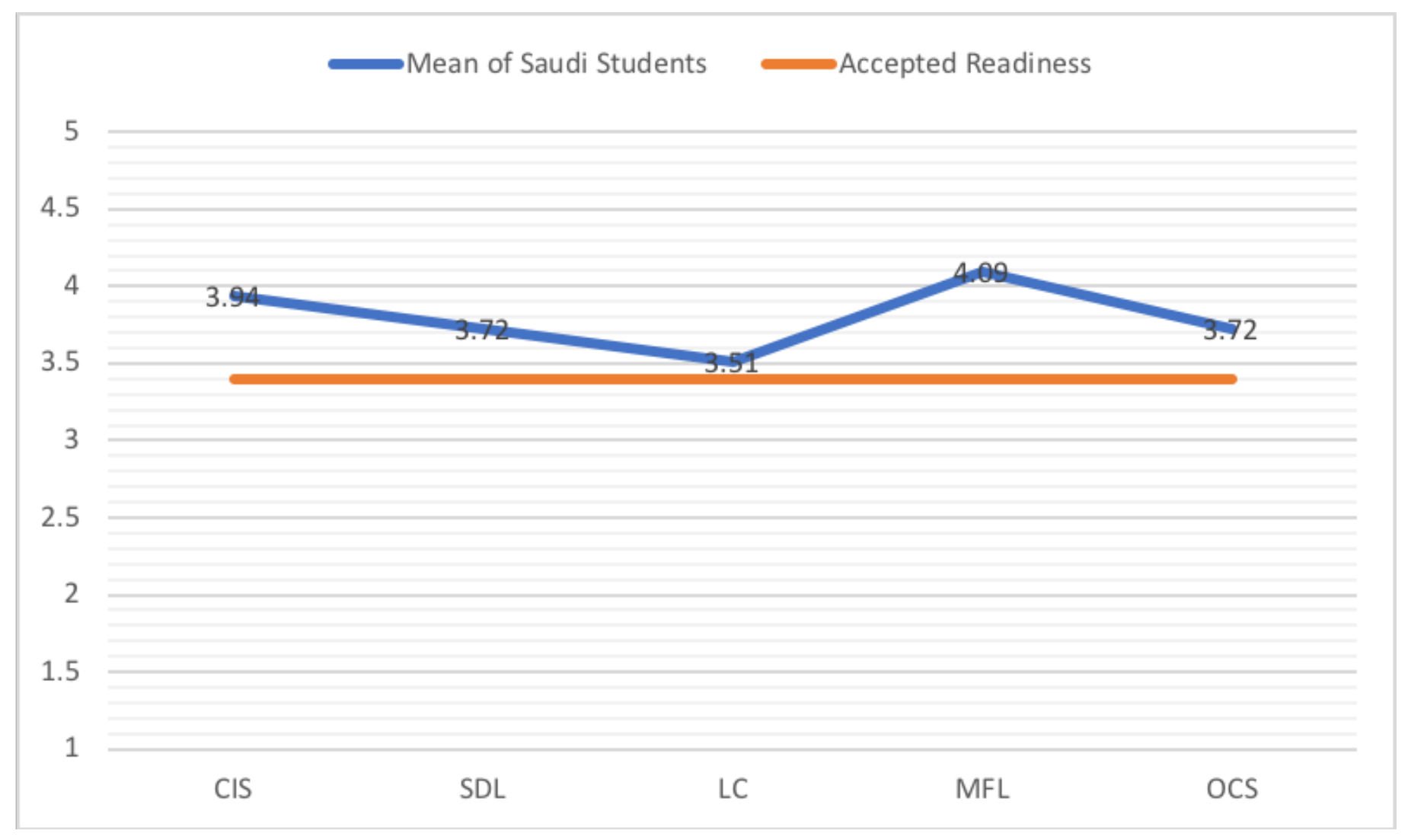

Fig. 1. Current Students' Readiness Level Compared to the Accepted Level

when students experience a problem with learning new tools. For instance, it has been found that the level of confidence in posting questions using online discussions is lower because of two reasons. Firstly, students avoid questioning because they are not sure about getting the right and timely response they seek for. Secondly, students might have the fear that the answers to their questions are already provided elsewhere and they should look for the answers. In both cases, motivating students and increasing the level of their willingness and courage towards online learning along with providing them necessary assistant and support by instructors, technical support team, and department can lead to improve students' online communication self-efficacy.

\section{CONCLUSION}

The improvements that have been adopted in education system in Saudi Arabia had a significant impact on the development of undergraduate students' skills and knowledge. Readiness to online learning is one of the most developed areas, where the level of students has been measured in this study. However, the need for more improvements is required where increasing this level of readiness can lead to better learning and understanding of practical concepts, such as SE concepts, during the adoption of online learning methods. This study contributed by measuring the current level of undergraduate students throughout the adoption of one of the most recognized readiness scales. Furthermore, the study contributed by investigating different dimensions of readiness and methods for improvements besides exploring how different factors correlate to constitute barriers that hinder the improvement in the readiness level among undergraduate students.

The recommendations of this research are multifaceted. Firstly, decision makers in educational institutes must adhere to the set of practices and processes that enable students to utilize online learning tools and methods and persevering high motivation. The practices can entail having well-trained instructors for online teaching, designing curriculum that links learning outcome with the new online tools and methods, and working on continuous support and help for students during the online learning process. Secondly, enriching students with the required knowledge and skills to overcome different challenges that they might face during the online learning. Students also need training courses and workshops to help them manage their time wisely and effectively during the online learning. Finally, faculty members are also required to have the necessary training and obtain the required knowledge and skills regarding online teaching to assist their students effectively.

\section{ACKNOWLEDGMENT}

The author extends his appreciation to the Deanship of Scientific Research at Saudi Electronic University for funding this work.

\section{REFERENCES}

[1] R. G. Saadé, X. He, and D. Kira, "Exploring dimensions to online learning," Computers in human behavior, vol. 23, no. 4, pp. 1721-1739, 2007. 
[2] J. Küsel, F. Martin, and S. Markic, “University students' readiness for using digital media and online learning-comparison between germany and the usa," Education Sciences, vol. 10, no. 11, p. 313, 2020.

[3] A. Alsolamy and R. Qureshi, "The proposal of a qualification based approach to teach software engineering course." International Arab Journal of Information Technology (IAJIT), vol. 12, no. 2, 2015.

[4] D. Warner, G. Christie, and S. Choy, "Readiness of vet clients for flexible delivery including on-line learning," Brisbane: Australian National Training Authority, 1998.

[5] M.-L. Hung, C. Chou, C.-H. Chen, and Z.-Y. Own, "Learner readiness for online learning: Scale development and student perceptions," Computers \& Education, vol. 55, no. 3, pp. 1080-1090, 2010.

[6] A. Sethi, A. Wajid, and A. Khan, "E-learning: Are we there yet?" Professional Medical Journal, vol. 26, no. 4, 2019.

[7] F. H. Chanchary and S. Islam, "Is saudi arabia ready for e-learning? a case study," in The 12th International Arab Conference on Information Technology, Naif Arab University for Security Sciences, Saudi Arabia, retrivied: January, vol. 20, 2011, p. 2017.

[8] A. Alahmari and R. J. Amirault, "The use of e-learning in highly domain-specific settings: Perceptions of female students and faculty in saudi arabia," Quarterly Review of Distance Education, vol. 18, no. 4, pp. 37-56, 2017.

[9] A. Heredia, R. C. Palacios, and A. de Amescua Seco, "A systematic mapping study on software process education." in SPETP@SPICE, 2015, pp. 7-17.

[10] M. R. Marques, A. Quispe, and S. F. Ochoa, "A systematic mapping study on practical approaches to teaching software engineering," in 2014 IEEE Frontiers in Education Conference (FIE) Proceedings. IEEE, 2014, pp. 1-8.

[11] D. Dicheva, C. Dichev, G. Agre, and G. Angelova, "Gamification in education: A systematic mapping study." Journal of Educational Technology \& Society, vol. 18, no. 3, 2015.

[12] M. M. Alhammad and A. M. Moreno, "Gamification in software engineering education: A systematic mapping," Journal of Systems and Software, vol. 141, pp. 131-150, 2018.

[13] V. Garousi, A. Rainer, P. Lauvås jr, and A. Arcuri, "Software-testing education: A systematic literature mapping," Journal of Systems and Software, p. 110570, 2020.

[14] K. Wendt, "Audience and content areas of online software engineering education and training: A systematic review," in Proceedings of the 52nd Hawaii International Conference on System Sciences, 2019.

[15] T. Carney, "Andragogy in action: Applying modern principles of adult learning," Canadian Journal of Communication, vol. 12, no. 1, 1986.

[16] A. Mora, E. Planas, and J. Arnedo-Moreno, "Designing game-like activities to engage adult learners in higher education," in Proceedings of the Fourth International Conference on Technological Ecosystems for Enhancing Multiculturality, 2016, pp. 755-762.

[17] R. B. Johnson and A. J. Onwuegbuzie, "Mixed methods research: A research paradigm whose time has come," Educational researcher, vol. 33, no. 7, pp. 14-26, 2004.

[18] J. W. Creswell and J. D. Creswell, Research design: Qualitative, quantitative, and mixed methods approaches. Sage publications, 2017.

[19] V. Braun and V. Clarke, "Using thematic analysis in psychology," Qualitative research in psychology, vol. 3, no. 2, pp. 77-101, 2006.

[20] J. F. Hair, W. C. Black, B. J. Babin, R. E. Anderson, R. L. Tatham et al., Multivariate data analysis. Prentice hall Upper Saddle River, NJ, 1998, vol. 5, no. 3.

[21] C. Fornell and D. F. Larcker, "Structural equation models with unobservable variables and measurement error: Algebra and statistics," 1981.

[22] C. H. Aydın and D. Tasci, "Measuring readiness for e-learning: Reflections from an emerging country," Journal of Educational Technology \& Society, vol. 8, no. 4, pp. 244-257, 2005.

[23] T. Tang, S. Rixner, and J. Warren, "An environment for learning interactive programming," in Proceedings of the 45th ACM technical symposium on Computer science education, 2014, pp. 671-676. 